\title{
High normal 2-hour plasma glucose is associated with insulin sensitivity and secretion that may predispose to type 2 diabetes
}

Received: 15 May 2004 / Accepted: 19 November 2004 / Published online: 12 March 2005

(C) Springer-Verlag 2005

\begin{abstract}
Aims/hypothesis: The aim of this study was to evaluate differences in insulin sensitivity, insulin secretion and risk factors for cardiovascular disease between subjects with a 2-h plasma glucose (2hPG) level within the normal range (NPG) and subjects with IGT, following a 75-g OGTT. We also aimed to determine the respective contributions made by $2 \mathrm{hPG}$ and fasting plasma glucose to the metabolic risk profile. Methods: We compared cardiovascular risk factors and insulin sensitivity and insulin secretion by using several indices calculated using measurements obtained during an OGTT. Subjects $(n=643$, age 18-71 years) were participants in the Québec Family Study and were categorised according to $2 \mathrm{hPG}$ as having low NPG $(2 \mathrm{hPG}<5.6 \mathrm{mmol} / \mathrm{l}$, the group median for normal values), high NPG (2hPG 5.6-7.7 mmol/l) or IGT (2hPG 7.8-11.0 mmol/l). Subjects with type 2 diabetes were excluded from all analyses. Results: Beta cell function and insulin sensitivity progressively decreased with increasing 2hPG. Compared with subjects with low NPG, subjects with high NPG were more insulin-resistant $(p<0.05)$ and had reduced insulin secretion (adjusted for insulin resis-
\end{abstract}

M. E. Piché · S. Lemieux

Department of Food Science and Nutrition, Laval University, Québec City, QC, Canada

M. E. Piché · S. Lemieux · S. J. Weisnagel

Lipid Research Center,

Laval University Hospital (CHUL) Research Center,

Québec City, QC, Canada

L. Pérusse · S. J. Weisnagel

Department of Social and Preventive Medicine,

Division of Kinesiology, Laval University,

Québec City, QC, Canada

S. J. Weisnagel $(\bowtie)$

Diabetes Research Unit, Endocrinology, S-27, Lipid Research

Centre, Laval University Health Centre, CHUQ,

2705 Bvld. LaurierSte-Foy,

Québec, G1V 4G2, Canada

e-mail: john.weisnagel@kin.msp.ulaval.ca

Tel.: +1-418-6542169

Fax: +1-418-6542792 tance) $(p<0.001)$. They also had higher plasma triglyceride concentrations $(p<0.01)$ and cholesterol:HDL cholesterol ratios $(p<0.05)$. These differences remained even after adjustment for age, sex, BMI and waist circumference. Multivariate analyses showed that $2 \mathrm{hPG}$ was closely associated with risk factors for diabetes and with cardiovascular variables, including triglycerides $(p<0.0001)$ and apolipoprotein B $(p<0.01)$. Conclusions/interpretation: These results show that deteriorations in glucose-insulin metabolism, which may predispose individuals to type 2 diabetes and cardiovascular disease, are already present in subjects with $2 \mathrm{hPG}$ concentrations within the high normal range. Independently of obesity, $2 \mathrm{hPG}$ was found to explain, in part, the variance observed in cardiovascular and diabetes risk factors. In addition, elevated $2 \mathrm{hPG}$ was associated with metabolic alterations that appear to be the most detrimental to metabolic health. Thus, $2 \mathrm{hPG}$ values within the high normal range may be an important marker for the identification of people at risk of complications related to type 2 diabetes.

Keywords Cardiovascular risk factors - Elevated 2-h plasma glucose $\cdot$ Fasting plasma glucose $\cdot$ Insulin secretion · Insulin sensitivity

Abbreviations 2hPG: plasma glucose - ADA: American Diabetes Association - Apo: apolipoprotein - CT: computed tomography - CVD: cardiovascular disease · DECODE: Diabetes Epidemiology: Collaborative Analysis of Diagnostic Criteria in Europe - GLM: general linear model - $\mathrm{HOMA}_{\mathrm{BC}}$ : homeostasis model assessment for beta cell function - $\mathrm{HOMA}_{\mathrm{IR}}$ : homeostasis model assessment for insulin resistance $\cdot$ ISI: insulin sensitivity index - MCR: metabolic clearance rate of glucose NPG: normal 2-h plasma glucose

\section{Introduction}

The term IGT (glycaemia between 7.8 and $11.0 \mathrm{mmol} / \mathrm{l}, 2 \mathrm{~h}$ after an OGTT) was first introduced in 1979 to replace 
borderline diabetes and other categories of hyperglycaemia $[1,2]$. There were clear indications that individuals with 2-h plasma glucose $(2 \mathrm{hPG})$ concentrations below $11.0 \mathrm{mmol} / 1$ but above normal concentrations had a greatly increased risk of subsequently developing type 2 diabetes [3]. In the latest reports from the World Health Organization and the American Diabetes Association (ADA), IGT is categorised as a stage in the natural history of glucose metabolism disorders $[4,5]$. However, the glycaemic cut-off value for IGT was not based on the risk of cardiovascular disease (CVD), and growing evidence suggests that the risk of cardiovascular events and the development of type 2 diabetes extends to concentrations below present diagnostic thresholds [6-8].

The results of prospective epidemiological studies have shown that the relationship between $2 \mathrm{hPG}$ levels and the subsequent risk of CVD extends to well below the diabetic cut-off value $[6,9-11]$. In fact, data from the prospective Whitehall Study demonstrated that coronary heart disease and stroke mortality after 10 years was increased by a factor of 1.5-2 in men whose post-load (50 g) capillary glucose was as low as $5.4 \mathrm{mmol} / \mathrm{l}$ [10]. In addition, a recent systematic overview and meta-regression analysis of several epidemiological studies also confirmed a graded relationship between $2 \mathrm{hPG}$ concentrations and cardiovascular risk and mortality [11].

Both impaired insulin sensitivity and insulin secretion are involved in the deterioration of glucose tolerance from the normal to the glucose intolerant state [12]. Whether defects in these glucose-insulin metabolism parameters are present in subjects with high normal $2 \mathrm{hPG}$ (NPG) is not well known. Also, the relationship with CVD risk factors is unclear. Many of the epidemiological studies performed to date did not take into account age, sex, BMI and, in particular, abdominal obesity when evaluating associations between glucose and cardiovascular risk factors. This is important because insulin sensitivity can be reduced with age and with increased central adiposity [13, 14].

In the 1997 report by the ADA, the expert committee recommended that only fasting plasma glucose concentrations $\geq 7.0 \mathrm{mmol} / 1$ be used for diagnosing type 2 diabetes in epidemiological studies and in routine clinical practice, and did not recommend using a 2-h OGTT [15]. However, postprandial hyperglycaemia is one of the earliest abnormalities detected in type 2 diabetes [16]. Furthermore, results from the Diabetes Epidemiology: Collaborative Analysis of Diagnostic Criteria in Europe (DECODE) study group showed that $2 \mathrm{hPG}$ was a better predictor of overall and CVD mortality than fasting plasma glucose when applied alone [17]. In addition, the Risk Factors in IGT for Atherosclerosis and Diabetes (RIAD) study showed that 2hPG was associated with increased carotid intima-media thickness, whereas fasting plasma glucose did not contribute to an increase in risk in multivariate analysis [18]. Thus, measurement of $2 \mathrm{hPG}$ may be necessary to more fully assess diabetes and CVD risk.

The aim of the present study was to evaluate differences in measures of insulin sensitivity, insulin secretion and CVD risk factors between subjects with NPG $(<7.8 \mathrm{mmol} / \mathrm{l})$ and subjects with IGT, taking into account expected differences in age, sex, body fat composition and distribution, and fasting plasma glucose. An additional goal was to determine the respective contributions made by $2 \mathrm{hPG}$ and fasting plasma glucose to the metabolic risk profile.

\section{Subjects and methods}

Subjects This cross-sectional study was conducted in 643 subjects (aged between 18 and 71 years) recruited by the Québec Family Study through advertising media in the Québec City metropolitan area. The Québec Family Study is an investigation of French-Canadian families, which was designed to study factors involved in the aetiology of obesity and its comorbidities [19]. It was comprised of three phases. Initially, a population-based sample of members of families was evaluated between 1979 and 1981. In phases 2 and 3, a sample of families from phase 1 was remeasured, and additional families, ascertained through obese probands $\left(\mathrm{BMI}>32 \mathrm{~kg} / \mathrm{m}^{2}\right)$, were recruited and incorporated in the cohort. All family members were invited to participate. The maximum cross-sectional sample of subjects from phases 2 and 3 who underwent an OGTT was analysed in the present study. Subjects were classified into different stages of glucose tolerance based on their $2 \mathrm{hPG}$ concentrations. Subjects with NPG values were divided into two subgroups according to the group median $(5.6 \mathrm{mmol} / \mathrm{l})$ in order to compare subjects with low NPG $(2 \mathrm{hPG}<5.6 \mathrm{mmol} / \mathrm{l})$ with those with high NPG $(2 \mathrm{hPG} \geq 5.6$ and $<7.8 \mathrm{mmol} / \mathrm{l})$. IGT was defined as a $2 \mathrm{hPG}$ level $\geq 7.8 \mathrm{mmol} / \mathrm{l}$ and $<11.1 \mathrm{mmol} / \mathrm{l}$, and type 2 diabetes was defined as a fasting plasma glucose concentration $\geq 7.0 \mathrm{mmol} / \mathrm{l}$ or a $2 \mathrm{hPG}$ concentration $\geq 11.1 \mathrm{mmol} / 1$. Subjects with type 2 diabetes were excluded from all analyses. All participants signed an informed consent document before entering the study, which was approved by the Laval University Medical Ethics Committee.

Anthropometric and blood pressure measurements The hydrostatic weighing technique was used to measure body density, and the mean of six valid measurements was used [20]. The percentage body fat was derived from body density using the equation of Siri [21]. Fat mass was calculated by multiplying the percentage body fat by body weight. Height, body weight and waist circumference were measured according to the procedures recommended at the Airlie Conference [22]. Waist circumference was measured in duplicate at the mid-point between the iliac crest and the last rib margin while the subject was in a standing position; the measurement was recorded to the nearest $\mathrm{mm}$. Systolic and diastolic blood pressures were measured in the right arm of seated participants.

Computed tomography Measurements of abdominal adipose tissue areas were performed by computed tomography (CT) at the abdominal level between the L4 and L5 vertebrae with a Siemens Somatom DRH scanner (Erlangen, Germany), following the procedures of Sjöström et al. as previously described [23, 24]. 
Oral glucose tolerance test A 75-g OGTT was performed in the morning after an overnight fast. For measurements of plasma glucose, insulin and C-peptide concentrations, blood samples were collected at $-15,0,15,30,45,60,90$, 120, 150 and 180 min in EDTA-containing tubes (Becton Dickinson, Franklin Lakes, NJ, USA) through a venous catheter placed in an antecubital vein. Plasma glucose was measured enzymatically, whereas plasma insulin was measured by RIA with polyethylene glycol separation [25, 26]. Plasma C-peptide levels were measured by a modification of the method of Heding [27], using polyclonal antibody A-4741 (Ventrex, Portland, ME, USA) and polyethylene glycol precipitation [26] as previously described [28]. The interassay $\mathrm{CV}$ was $1.3 \%$ for a basal glucose value set at $5.0 \mathrm{mmol} / 1$.

The equations for the indices used to assess beta cell function and insulin sensitivity are shown in Table 1. Beta cell function in the fasting state was assessed using the homeostasis model assessment for beta cell function $\left(\mathrm{HOMA}_{\mathrm{BC}}\right)$. The Stumvoll first-phase index, the insulin:glucose ratio, the C-peptide:glucose ratio and the insulinogenic index were used to assess beta cell function during the first 30 min of the OGTT. Insulin sensitivity in the fasting state was estimated using the homeostasis model assessment for insulin resistance $\left(\mathrm{HOMA}_{\mathrm{IR}}\right)$. The insulin sensitivity during the OGTT was estimated using the Cederholm index, the Matsuda index, Metabolic Clearance Rate (MCR) of glucose, and the Insulin Sensitivity Index (ISI). These indices have been validated and show good correlations with more robust methods of measuring insulin secretion and insulin sensitivity [29-35].

Plasma lipid-lipoprotein profile Blood samples were collected from an antecubital vein into vacutainer tubes containing EDTA after a 12-h overnight fast. Cholesterol and triglyceride concentrations were determined enzymatically in plasma and lipoprotein fractions using a Technicon RA500 analyser (Bayer Corporation, Tarrytown, NY, USA) and enzymatic reagents obtained from Randox (Crumlin,
UK). Plasma lipoprotein fractions (VLDL, LDL and HDL) were isolated using previously described procedures [36]. Plasma apolipoprotein B (apoB) concentrations were measured by the rocket immuno-electrophoretic method of Laurell [37].

Statistical analysis Statistical analyses were performed using the SAS statistical software package, Version 8.2 (SAS Institute, Cary, NC, USA). Morphological and metabolic variables were compared between the groups by using an ANOVA with the general linear model (GLM) procedure. Group comparisons for anthropometric variables (BMI, body fat mass, waist circumference, visceral and subcutaneous adipose tissue) were made with adjustment for age and sex. All other variables were adjusted for age, sex, BMI and waist circumference. BMI was used to estimate body fat composition, whereas waist circumference was found to reflect body fat distribution [38]. The absence of colinearity between these two variables was confirmed by a regression analysis using the variance inflation factor. In order to determine the contribution of fasting plasma glucose to the deterioration of glucose-insulin homeostasis with increasing $2 \mathrm{hPG}$, fasting plasma glucose was added as a covariable to the original model, which included age, sex, BMI and waist circumference. For analyses with indices of insulin secretion, comparisons were performed with or without adjustment for an index of insulin sensitivity (Matsuda index).

Multiple regression analyses were performed to determine the respective contributions of $2 \mathrm{hPG}$ and fasting plasma glucose to the variance of several metabolic and glucose-insulin homeostasis variables using a GLM procedure. In the multiple regression model, the effects of age, sex, BMI, waist circumference, fasting plasma glucose and $2 \mathrm{hPG}$ on the cardiovascular and diabetes risk factors were included. Insulin sensitivity and secretion were also included in the second and third models, respectively. The absence of colinearity between fasting plasma glucose and $2 \mathrm{hPG}$ was confirmed by a regression analysis using the

Table 1 Indices of beta cell function and insulin sensitivity derived from fasting and OGTT measurements of glucose, insulin and C-peptide

\begin{tabular}{|c|c|c|}
\hline Index & Formula & Reference \\
\hline \multicolumn{3}{|l|}{ Indices of beta cell function } \\
\hline $\mathrm{HOMA}_{\mathrm{BC}}$ & $\left(20 \times\right.$ insulin $\left._{0}\right) /\left(\right.$ glucose $\left._{0}-3.5\right)$ & [29] \\
\hline Stumvoll first-phase index & $700+\left[1,283+\left(1.829 \times\right.\right.$ insulin $\left._{30}\right)-\left(138.7 \times\right.$ glucose $\left._{30}\right)+\left(3.372 \times\right.$ insulin $\left.\left._{0}\right)\right]$ & {$[30]$} \\
\hline Insulinogenic index & $\left(\right.$ insulin $_{30}-$-insulin $\left._{0}\right) /\left(\right.$ glucose $_{30}-$ glucose $\left._{0}\right)$ & [31] \\
\hline Insulin $30 \mathrm{~min} /$ glucose $30 \mathrm{~min}$ & insulin $_{30} /$ glucose $_{30}$ & {$[32]$} \\
\hline C-peptide $30 \mathrm{~min} /$ glucose $30 \mathrm{~min}$ & peptide $_{30} /$ glucose $_{30}$ & {$[33]$} \\
\hline C-peptide:glucose ratio & $\left(\right.$ peptide $_{30}-$ peptide $\left._{0}\right) /\left(\right.$ glucose $_{30}-$ glucose $\left._{0}\right)$ & \\
\hline \multicolumn{3}{|l|}{ Indices of insulin sensitivity } \\
\hline $\mathrm{HOMA}_{\mathrm{IR}}$ & $1 /\left[\left(\right.\right.$ insulin $_{0} \times$ glucose $\left.\left._{0}\right) / 22.5\right]$ & {$[29]$} \\
\hline Cederholm index & $\begin{array}{l}{\left[75,000+\left(\text { glucose }_{0}-\text { glucose }_{120}\right) \times 1.15 \times 180 \times 0.19 \times \text { weight }\right] /\left[120 \times \log \left(\text { insulin }_{\text {mean }}\right) \times\right.} \\
\left.\text { glucose }_{\text {mean }}\right]\end{array}$ & {$[34]$} \\
\hline Matsuda index & $10,000 / \sqrt{\left(\text { glucose }_{0} \times \text { insulin }_{0}\right) \times\left(\text { glucose }_{\text {mean }} \times \text { insulin }_{\text {mean }}\right)}$ & {$[35]$} \\
\hline MCR index & $18.8-(0.271 \times$ BMI $)-\left(0.0052 \times\right.$ insulin $\left._{120}\right)-\left(0.27 \times\right.$ glucose $\left._{90}\right)$ & {$[30]$} \\
\hline ISI & $0.226-(0.0032 \times \mathrm{BMI})-\left(0.0000645 \times\right.$ insulin $\left._{120}\right)-\left(0.00375 \times\right.$ glucose $\left._{90}\right)$ & {$[30]$} \\
\hline
\end{tabular}


variance inflation factor. The source of variation in metabolic variables was calculated using the type III sum of squares. This sum of squares applies to unbalanced study designs and quantifies the effects of an independent variable after adjustment for all other variables included in the model.

Participants taking antihypertensive or lipid-lowering medication were excluded from comparisons of plasma lipid-lipoprotein and hypertension variables $(n=131)$. The critical $p$ value for significance was set at 0.05 . Several variables required logarithmic transformation in order to improve their distribution (body fat mass, visceral adipose tissue, triglycerides, fasting plasma glucose, $2 \mathrm{hPG}$, glucose area, fasting insulin, insulin area, $\mathrm{HOMA}_{\mathrm{BC}}$, the insulinogenic index, insulin $30 \mathrm{~min} /$ glucose $30 \mathrm{~min}$, the Stumvoll first-phase index, $\mathrm{HOMA}_{\mathrm{IR}}$ and the Matsuda index).

\section{Results}

Table 2 shows the physical characteristics of the subjects divided into three categories according to $2 \mathrm{hPG}$. Subjects in the high-NPG and IGT groups were older than those in the low-NPG group. In addition, BMI and waist circumference were significantly higher in subjects with high NPG and IGT than in subjects with low NPG $(p<0.001)$. Visceral and subcutaneous adipose tissue areas were increased in subjects with high NPG and IGT compared with subjects with low NPG (age- and sex-adjusted values) $(p<0.01)$. Visceral and subcutaneous adipose tissue areas were also significantly higher in subjects with IGT than in subjects with high NPG. In addition, fasting plasma triglycerides and the ratio of cholesterol:HDL cholesterol were significantly higher in subjects with high NPG than in subjects characterised by low NPG $(p<0.05)$, even after adjustment for age, sex, BMI and waist circumference. No significant differences were observed between subjects with IGT and subjects with high NPG with respect to HDL cholesterol, triglycerides and the ratio of cholesterol:HDL cholesterol. However, triglyceride concentrations showed a trend of lower values in the high-NPG group compared with those in the IGT group $(p=0.07)$. Subjects with IGT were characterised by higher levels of plasma triglycerides, total cholesterol and apoB compared with the group with low NPG $(p<0.01)$.

As could be expected from the definition, $2 \mathrm{hPG}$ concentrations differed significantly between the three $2 \mathrm{hPG}$ categories (Table 3). No significant differences in fasting plasma glucose concentrations were observed between the high-NPG and low-NPG groups. Significant differences in insulin and C-peptide concentrations were observed between subjects with IGT and subjects with NPG $(p<0.01)$. Glucose and C-peptide AUCs were significantly higher in subjects with high NPG than in subjects with low NPG. The glucose and C-peptide AUCs were also higher in the IGT group than in the low- and high-NPG groups $(p<0.01)$. Among subjects with NPG, insulin sensitivity was significantly reduced in the high-NPG group compared with that in the low-NPG group $(p<0.01)$. In fact, indicators of insulin sensitivity, such as the Cederholm, Matsuda, ISI and MCR indices, were all significantly reduced in subjects with high NPG compared with those in subjects with low NPG $(p<0.01)$. In addition, insulin sensitivity (as estimated using these indices) was significantly lower in the IGT group than in the two NPG groups $(p<0.001)$.
Table 2 Physical characteristics, blood pressure and lipidlipoprotein profile in the total sample divided according to their $2 \mathrm{hPG}$ concentrations

Data are means \pm SD. Statistical analyses were performed on values adjusted for age and sex for body fat composition and distribution variables, and on values adjusted for age, sex, BMI and waist circumference for all other variables a $p<0.05$ vs individuals with $2 \mathrm{hPG}<5.6 \mathrm{mmol} / 1$ ${ }^{\mathrm{b}}<<0.05$ vs individuals with 2hPG between 5.6 and 7.8 $\mathrm{mmol} / \mathrm{l}$

${ }^{\mathrm{c}}$ Individuals using antihypertensive or lipid-lowering medication were excluded from all analyses of blood pressure and lipid-lipoprotein profile

\begin{tabular}{|c|c|c|c|}
\hline & \multicolumn{3}{|c|}{ 2hPG category $(\mathrm{mmol} / \mathrm{l})$} \\
\hline & $\begin{array}{l}\text { Low NPG }<5.6 \\
(n=256)\end{array}$ & $\begin{array}{l}\text { High NPG 5.6-7.7 } \\
(n=271)\end{array}$ & $\begin{array}{l}\text { IGT 7.8-11.0 } \\
(n=116)\end{array}$ \\
\hline \multicolumn{4}{|l|}{ Physical characteristics } \\
\hline Sex, men/women (\%) & $43 / 57$ & $45 / 55$ & $42 / 58$ \\
\hline Age (years) & $37.7 \pm 13.9$ & $42.3 \pm 14.5^{\mathrm{a}}$ & $48.7 \pm 14.3^{\mathrm{a}, \mathrm{b}}$ \\
\hline BMI $\left(\mathrm{kg} / \mathrm{m}^{2}\right)$ & $25.5 \pm 4.8$ & $28.1 \pm 7.5^{\mathrm{a}}$ & $31.3 \pm 8.8^{\mathrm{a}, \mathrm{b}}$ \\
\hline Body fat mass (kg) & $18.7 \pm 10.4$ & $23.6 \pm 14.1^{\mathrm{a}}$ & $30.7 \pm 17.3^{\mathrm{a}, \mathrm{b}}$ \\
\hline Waist circumference $(\mathrm{cm})$ & $82.8 \pm 13.5$ & $89.5 \pm 18.2^{\mathrm{a}}$ & $98.1 \pm 19.6^{\mathrm{a}, \mathrm{b}}$ \\
\hline $\begin{array}{l}\text { Visceral adipose tissue } \\
\left(\mathrm{cm}^{2}\right)\end{array}$ & $84 \pm 51$ & $113 \pm 71^{\mathrm{a}}$ & $159 \pm 79^{\mathrm{a}, \mathrm{b}}$ \\
\hline $\begin{array}{l}\text { Subcutaneous adipose } \\
\text { tissue }\left(\mathrm{cm}^{2}\right)\end{array}$ & $240 \pm 143$ & $295 \pm 173^{\mathrm{a}}$ & $345 \pm 180^{\mathrm{a}, \mathrm{b}}$ \\
\hline \multicolumn{4}{|l|}{ Blood pressure $(\mathrm{mmHg})^{\mathrm{c}}$} \\
\hline Systolic & $111 \pm 12$ & $113 \pm 14$ & $116 \pm 13$ \\
\hline Diastolic & $69 \pm 9$ & $69 \pm 10$ & $72 \pm 9$ \\
\hline \multicolumn{4}{|l|}{ Lipid-lipoprotein profile $^{c}$} \\
\hline Total cholesterol $(\mathrm{mmol} / \mathrm{l})$ & $4.51 \pm 0.89$ & $4.74 \pm 0.97$ & $5.06 \pm 1.00^{\mathrm{a}}$ \\
\hline LDL cholesterol (mmol/l) & $2.77 \pm 0.78$ & $2.94 \pm 0.86$ & $3.11 \pm 0.87$ \\
\hline HDL cholesterol (mmol/l) & $1.25 \pm 0.31$ & $1.18 \pm 0.31$ & $1.20 \pm 0.26$ \\
\hline $\begin{array}{l}\text { Cholesterol : HDL } \\
\text { cholesterol ratio }\end{array}$ & $3.78 \pm 1.07$ & $4.26 \pm 1.38^{\mathrm{a}}$ & $4.39 \pm 1.15$ \\
\hline Triglycerides (mmol/l) & $1.12 \pm 0.58$ & $1.38 \pm 0.66^{\mathrm{a}}$ & $1.68 \pm 0.68^{\mathrm{a}}$ \\
\hline
\end{tabular}


Table 3 Plasma glucose-insulin homeostasis variables in the study population stratified according to $2 \mathrm{hPG}$ concentration

Data are means \pm SD. Statistical analyses were performed on values adjusted for age, sex, BMI and waist circumference, except for the Cederholm index, the Matsuda index, the MCR and the ISI, where analyses were performed on values adjusted for age, sex and waist circumference

${ }^{\mathrm{a}} p<0.05$ vs individuals with 2hPG $<5.6 \mathrm{mmol} / 1$ ${ }^{\mathrm{b}} p<0.05$ vs individuals with 2hPG between 5.6 and $7.8 \mathrm{mmol} / \mathrm{l}$

Fig. 1 Indices of insulin secretion in 681 subjects according to their 2-h plasma glucose $(2 h P G)$ categories. Dashed bars are subjects with a low normal 2hPG (low NPG); open bars are subjects with high NPG; closed bars are subjects with IGT. Data are presented as least square means \pm SE, adjusted for age, sex, BMI, waist circumference and insulin sensitivity (Matsuda index). Asterisks indicate significant differences between groups: $* p<0.05, * * p<0.01$, $* * * p<0.0001$. Values are expressed as inverse log-transformed values
2hPG category $(\mathrm{mmol} / \mathrm{l})$

Low NPG <5.6 High NPG 5.6-7.7 IGT 7.8-11.0

Glucose-insulin homeostasis

Fasting plasma glucose $(\mathrm{mmol} / \mathrm{l})$

2hPG (mmol/l)

Glucose AUC (mmol/l)

Insulin AUC $\left(\times 10^{3} \mathrm{pmol} / \mathrm{l}\right)$

Fasting C-peptide (pmol/l)

$\begin{array}{cc}4.99 \pm 0.45 & 5.17 \pm 0.46 \\ 4.69 \pm 0.65 & 6.57 \pm 0.59^{\mathrm{a}} \\ 996.0 \pm 133.1 & 1237.8 \pm 140.4^{\mathrm{a}} \\ 63.8 \pm 35.2 & 76.2 \pm 44.5 \\ 739.5 \pm 303.1 & 856.6 \pm 393.5 \\ 482.2 \pm 174.5 & 563.8 \pm 216.8^{\mathrm{a}}\end{array}$

$5.51 \pm 0.63^{\mathrm{a}, \mathrm{b}}$

$8.96 \pm 0.87^{\mathrm{a}, \mathrm{b}}$

$1577.0 \pm 170.3^{\mathrm{a}, \mathrm{b}}$

C-peptide AUC $\left(\times 10^{3} \mathrm{pmol} / \mathrm{l}\right)$

$482.2 \pm 174.5$

$114.3 \pm 74.3^{\mathrm{a}, \mathrm{b}}$

Indices of insulin sensitivity

Fasting insulin (pmol/l)

$57.2 \pm 32.3$

$69.8 \pm 45.7$

$2.16 \pm 1.35$

$2.73 \pm 1.89$

Cederholm index

$19.9 \pm 3.5$

$15.2 \pm 2.7^{\mathrm{a}}$

Matsuda index

$19.2 \pm 18.7$

MCR OGTT

$29.0 \pm 1.9$

$14.7 \pm 14.8^{\mathrm{a}}$

$1105.2 \pm 581.0^{\mathrm{a}, \mathrm{b}}$

$740.4 \pm 281.6^{\mathrm{a}, \mathrm{b}}$

ISI OGTT
$27.0 \pm 3.0^{\mathrm{a}}$

$0.58 \pm 0.04^{\mathrm{a}}$
$102.7 \pm 69.7^{\mathrm{a}, \mathrm{b}}$

$4.32 \pm 3.32^{\mathrm{a}, \mathrm{b}}$

$10.4 \pm 1.8^{\mathrm{a}, \mathrm{b}}$

$8.7 \pm 5.1^{\mathrm{a}, \mathrm{b}}$

$23.5 \pm 4.4^{\mathrm{a}, \mathrm{b}}$

$0.54 \pm 0.05^{\mathrm{a}, \mathrm{b}}$
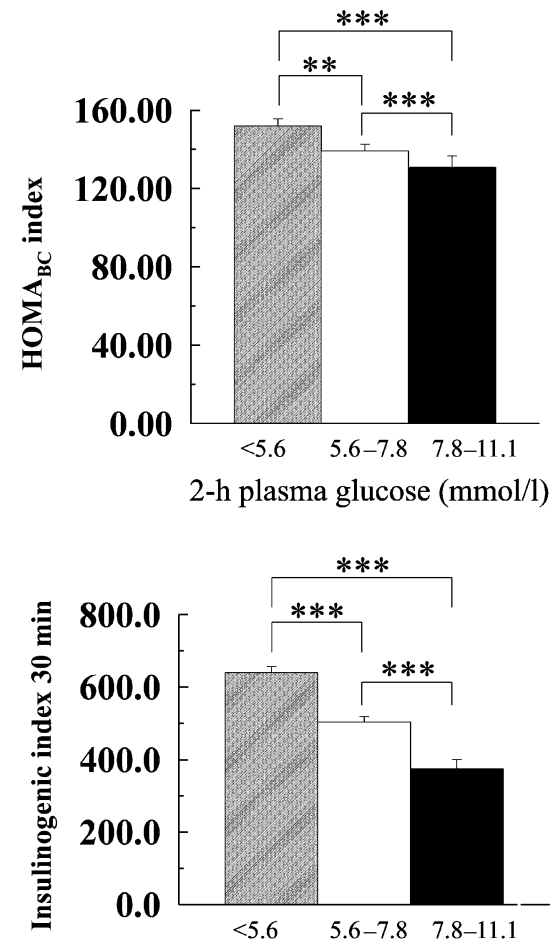

2-h plasma glucose $(\mathrm{mmol} / \mathrm{l})$

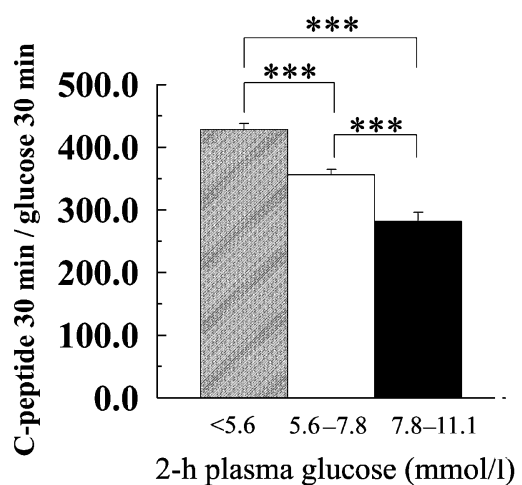

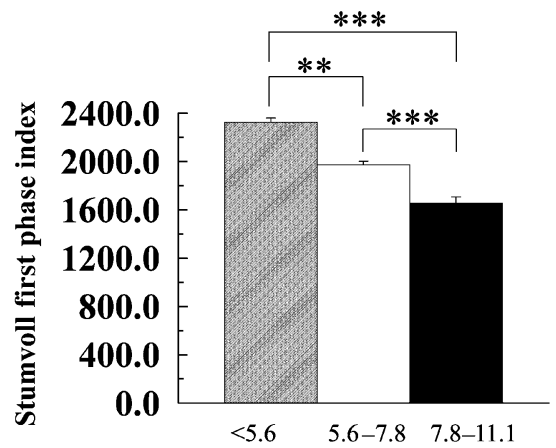

2-h plasma glucose $(\mathrm{mmol} / \mathrm{l})$

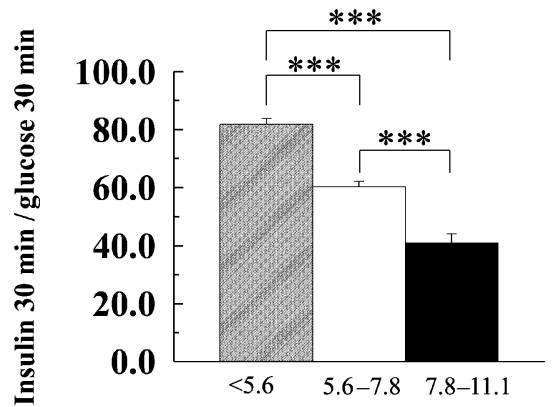

2-h plasma glucose (mmol/l)

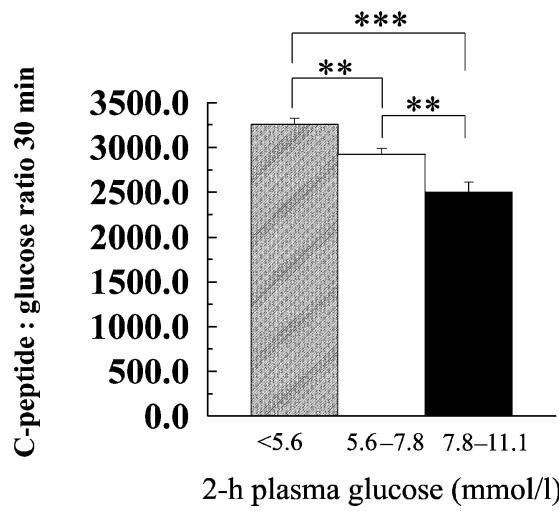


Insulin secretion progressively increased as insulin sensitivity decreased (data not shown). However, taking into account variations in insulin sensitivity in the model, indices of insulin secretion progressively decreased with increasing $2 \mathrm{hPG}$, and significant differences were observed between each of the categories (Fig. 1). Beta cell function (adjusted for insulin sensitivity), as estimated by the $\mathrm{HOMA}_{\mathrm{BC}}$ index, the Stumvoll first-phase index, the insulinogenic index, insulin $30 \mathrm{~min} /$ glucose $30 \mathrm{~min}$, C-peptide $30 \mathrm{~min} /$ glucose $30 \mathrm{~min}$ and the C-peptide:glucose ratio, was significantly reduced in the high-NPG group compared with that in the low-NPG group $(p<0.001)$. Indices of insulin secretion were also significantly decreased in subjects with IGT $(p<0.0001)$.

After incorporating fasting plasma glucose as a covariable in our initial model, which included age, sex, BMI and waist circumference, all previously observed differences between the three groups in terms of cardiovascular risk profile, insulin sensitivity and insulin secretion parameters were maintained (data not shown).

Multivariate regression analysis was used to determine the independent contributions of $2 \mathrm{hPG}$ and fasting plasma glucose to the variance in cardiovascular and diabetes risk factors (insulin sensitivity and insulin secretion) in the total sample (Table 4). After including age, sex, BMI, waist

Table 4 Multivariate regression analyses showing the independent contribution of fasting plasma glucose, 2hPG, insulin sensitivity and insulin secretion to the variance of metabolic variables in the total sample

\begin{tabular}{|c|c|c|c|c|c|c|c|c|c|c|}
\hline & \multicolumn{10}{|c|}{ Dependent variable } \\
\hline & $\begin{array}{l}\text { LDL } \\
\text { cholesterol }\end{array}$ & $\begin{array}{l}\text { HDL } \\
\text { cholesterol }\end{array}$ & $\begin{array}{l}\text { Cholesterol: } \\
\text { HDL } \\
\text { cholesterol } \\
\text { ratio }\end{array}$ & Triglycerides & ApoB & $\begin{array}{l}\text { Systolic } \\
\text { BP }\end{array}$ & $\begin{array}{l}\text { Diastolic } \\
\text { BP }\end{array}$ & $\begin{array}{l}\text { Matsuda } \\
\text { index }\end{array}$ & $\begin{array}{l}\text { Stumvoll } \\
\text { index }\end{array}$ & $\begin{array}{l}\text { Insulinogenic } \\
\text { index }\end{array}$ \\
\hline \multicolumn{11}{|l|}{ Model 1} \\
\hline BMI & $0.006^{\mathrm{c}}$ & - & $0.009^{\mathrm{b}}$ & $0.004^{\mathrm{c}}$ & $0.012^{\mathrm{b}}$ & - & - & - & - & - \\
\hline $\begin{array}{l}\text { Waist } \\
\text { circumference }\end{array}$ & $0.014^{\mathrm{b}}$ & $0.018^{\mathrm{a}}$ & $0.039^{\mathrm{a}}$ & $0.024^{\mathrm{a}}$ & $0.027^{\mathrm{a}}$ & - & $0.006^{\mathrm{c}}$ & $0.133^{\mathrm{a}}$ & $0.030^{\mathrm{a}}$ & $0.021^{\mathrm{a}}$ \\
\hline $\begin{array}{l}\text { Fasting plasma } \\
\text { glucose }\end{array}$ & $0.013^{\mathrm{b}}$ & - & - & - & - & - & - & $0.052^{\mathrm{a}}$ & - & $0.015^{\mathrm{b}}$ \\
\hline BMI & $0.007^{\mathrm{c}}$ & - & $0.008^{\mathrm{b}}$ & - & $0.011^{\mathrm{b}}$ & - & - & & - & - \\
\hline $\begin{array}{l}\text { Waist } \\
\text { circumference }\end{array}$ & $0.015^{\mathrm{b}}$ & $0.011^{\mathrm{a}}$ & $0.028^{\mathrm{a}}$ & $0.010^{\mathrm{b}}$ & $0.021^{\mathrm{a}}$ & - & - & & - & - \\
\hline $\begin{array}{l}\text { Fasting plasma } \\
\text { glucose }\end{array}$ & $0.009^{\mathrm{b}}$ & - & - & - & - & - & - & & $0.048^{\mathrm{a}}$ & $0.006^{\mathrm{b}}$ \\
\hline $2 \mathrm{hPG}$ & - & - & - & $0.018^{\mathrm{a}}$ & $0.007^{\mathrm{c}}$ & - & - & & $0.093^{\mathrm{a}}$ & $0.071^{\mathrm{a}}$ \\
\hline $\begin{array}{l}\text { Insulin } \\
\text { sensitivity }\end{array}$ & - & $0.012^{\mathrm{b}}$ & $0.012^{\mathrm{b}}$ & $0.033^{\mathrm{a}}$ & - & $0.004^{\mathrm{c}}$ & - & & $0.340^{\mathrm{a}}$ & $0.395^{\mathrm{a}}$ \\
\hline \multicolumn{11}{|l|}{ Model 3} \\
\hline Age & $0.091^{\mathrm{a}}$ & $0.031^{\mathrm{a}}$ & $0.015^{\mathrm{b}}$ & $0.034^{\mathrm{a}}$ & $0.079^{\mathrm{a}}$ & $0.16^{\mathrm{a}}$ & $0.06^{\mathrm{a}}$ & - & & \\
\hline Insulin secretion & - & $0.008^{\mathrm{b}}$ & $0.008^{\mathrm{b}}$ & $0.022^{\mathrm{a}}$ & - & - & - & $0.238^{\mathrm{a}}$ & & \\
\hline
\end{tabular}

Values shown are partial $r^{2}$, which refers to the variance explained by the variable in the model. Variables that do not independently contribute to the variance in the model are indicated by a dash in the table

${ }^{\mathrm{a}} p<0.0001$

${ }^{\mathrm{b}} p<0.01$

${ }^{c} p<0.05$ 
circumference, fasting plasma glucose and $2 \mathrm{hPG}$ in a GLM multiple regression model, $2 \mathrm{hPG}$ was found to be an independent predictor of many metabolic variables, including triglycerides $\left(r^{2}=0.033 ; p<0.0001\right)$, apoB $\left(r^{2}=0.009\right.$; $p<0.01$ ), insulin sensitivity as defined by the Matsuda index $\left(r^{2}=0.034 ; p<0.0001\right)$, and insulin secretion as defined by the Stumvoll first-phase index $\left(r^{2}=0.027 ; p<0.0001\right)$ and the insulinogenic index $\left(r^{2}=0.013 ; p<0.001\right)$. Fasting plasma glucose was an independent predictor of LDL cholesterol $\left(r^{2}=0.013 ; p<0.01\right)$, insulin sensitivity (Matsuda index) and insulin secretion (Stumvoll first-phase index) $(p<0.01)$.

When insulin sensitivity was included in the multivariate model (Model 2, Table 4), it was found to be an independent predictor of cardiovascular risk factors, including HDL cholesterol, the cholesterol:HDL cholesterol ratio, triglycerides, systolic blood pressure, and insulin secretion as defined by the Stumvoll first-phase and insulinogenic indices $\left(0.004 \leq r^{2} \leq 0.395\right)$. Analyses including insulin secretion in our model showed that it was independently associated with HDL cholesterol, the cholesterol:HDL cholesterol ratio, triglycerides and insulin sensitivity (Matsuda index), but to a lesser degree compared with insulin sensitivity $\left(0.008 \leq r^{2} \leq 0.238\right)$ (Model 3, Table 4).

\section{Discussion}

Since the ADA Expert Committee recommended that fasting plasma glucose alone be used to diagnose type 2 diabetes in both clinical and epidemiological settings, the clinical significance of elevated $2 \mathrm{hPG}$ has been re-evaluated. Previous studies have shown that $2 \mathrm{hPG}$ concentrations following a 75-g OGTT predict all-cause, cardiovascular and coronary mortality $[9,11,17]$. Epidemiological studies suggest that there are no threshold values for increased mortality with higher $2 \mathrm{hPG}$ and fasting plasma glucose [11]. The results of the DECODE study recently demonstrated that abnormalities in $2 \mathrm{hPG}$ were better predictors of all-cause mortality and mortality due to CVD than fasting plasma glucose alone [17].

In this study, we calculated several indices of insulin sensitivity and insulin secretion derived from measurements of plasma glucose and insulin concentrations in the fasting state and during the OGTT. We subsequently compared these indices and the cardiovascular risk profiles of subjects with $2 \mathrm{hPG}$ values currently considered normal $(<7.8 \mathrm{mmol} / \mathrm{l})$ with those of subjects with IGT.

Our results show that subjects with PG values within the high normal range (high NPG) were characterised by increased obesity and a less favourable lipid-lipoprotein profile (higher plasma triglyceride concentrations and higher cholesterol : HDL cholesterol ratios), even after adjustment for age, sex, BMI and waist circumference. Furthermore, the lipid-lipoprotein profile of the high-NPG group was very similar to that observed in the IGT group, suggesting dyslipidaemia even at this level. These results may partly explain the conclusions of a recent systematic overview and meta-regression analysis of epidemiological studies, which found a progressive association between $2 \mathrm{hPG}$ and $\mathrm{CVD}$ risk extending below the diabetic threshold [11].

Insulin sensitivity seems to be considerably reduced in subjects with high NPG, even after adjustment for age, sex, BMI and waist circumference. Hence, subjects in the highNPG group could be at higher risk of type 2 diabetes, as was found in a longitudinal study of Pima Indians, with insulin sensitivity declining at an early stage during the transition from normal glucose tolerance to type 2 diabetes [39].

It is known that insulin secretion and sensitivity follow a hyperbolic relationship, which emphasises the importance of considering insulin sensitivity when evaluating beta cell function [40, 41]. In our study, after adjustment for age, sex, adiposity and insulin sensitivity, insulin secretion progressively declined with increasing $2 \mathrm{hPG}$ across the normal range of values. Thus, a relative defect in insulin secretion may already be present in subjects with high NPG, supporting data from Weyer and colleagues, who suggested that defects in beta cell function are present even before the diagnostic criteria for IGT and type 2 diabetes have been met [42].

Taking into account body fat distribution by adjusting for abdominal visceral adipose tissue accumulation, as measured by CT scan in a subgroup of subjects $(n=587)$, did not alter the results (data not shown).

In order to evaluate the respective contribution of fasting plasma glucose to this continuous deterioration of glucoseinsulin homeostasis with increasing $2 \mathrm{hPG}$, fasting plasma glucose was incorporated as a covariable in our analyses (data not shown). Results remained unchanged, suggesting that the less favourable metabolic profile associated with high NPG was only weakly affected by fasting plasma glucose levels. An analysis performed on our total sample revealed a significant correlation between fasting plasma glucose and $2 \mathrm{hPG}(r=0.45 ; p<0.05)$ (data not shown). Multivariate analyses showed that both $2 \mathrm{hPG}$ and fasting plasma glucose were independent predictors of many metabolic variables, but $2 \mathrm{hPG}$ was the stronger predictor. When insulin sensitivity was included in our multivariate model, it was found to explain a greater proportion of the variance in cardiovascular risk factors compared with $2 \mathrm{hPG}$, suggesting that the insulin resistance observed in subjects with elevated $2 \mathrm{hPG}$ accounts for an important part of the variance between the three $2 \mathrm{hPG}$ groups in terms of the metabolic risk profile. Therefore, measurements of insulin sensitivity may be very important for the identification of subjects at risk of type 2 diabetes. This reasoning supports a recent study by Festa and colleagues, who suggested that the pattern of risk factors (including increased insulin resistance) associated with isolated IGT identifies a subgroup of non-diabetic individuals who are likely to benefit from early intervention aimed at preventing the development of CVD and type 2 diabetes [43]. Multivariate analyses also showed that insulin secretion was not a significant predictor of cardiovascular risk factors.

In conclusion, our results show that there are significant differences in glucose-insulin metabolism among subjects with $2 \mathrm{hPG}$ values within the normal range (independent of 
age, sex, BMI, waist circumference and fasting plasma glucose). Both insulin secretion and insulin sensitivity decrease with increasing $2 \mathrm{hPG}$. In addition, there are significant differences in CVD risk factors between NPG subcategories, even after adjustment for age, sex, body fat composition and distribution. This study also shows that both $2 \mathrm{hPG}$ and fasting plasma glucose are associated with some specific alterations in the risk profile for CVD, with $2 \mathrm{hPG}$ possibly making a more important contribution. Thus, high NPG is a marker of a series of CVD and diabetes risk factors, independent of age, sex, adiposity and fasting plasma glucose. Since the $2 \mathrm{hPG}$ also provides important information on glucose tolerance status, the underlying clinical relevance of this marker, even at concentrations within the normal range, should probably be taken into account in the overall evaluation of subjects at risk of CVD and type 2 diabetes.

Acknowledgements The authors would like to express their gratitude to the subjects, for their excellent collaboration, and to the staff of the Lipid Research Center, the Physical Activity Sciences Laboratory (Laval University), and the Diabetes Research Unit, for their contribution to this study. We especially want to thank L. Allard, S. Brulotte, L. Bargone, G. Fournier, H. Bessette and C. Leblanc for their help in the collection and analysis of the data. This study was supported by the Canadian Diabetes Association and by the Canadian Institutes of Health Research (grant nos. MT-14014 and MGC15187). M. E. Piché is the recipient of a training fellowship from the Laval University Foundation and the Québec Diabetes Foundation.

\section{References}

1. National Diabetes Data Group (1979) Classification and diagnosis of diabetes and other categories of glucose intolerance. Diabetes 28:1039-1057

2. World Health Organization Expert Committee on Diabetes Mellitus (1980) Technical Report Series 646, second report. World Health Organization, Geneva

3. Jarrett RJ, Keen H, Fuller JH, McCartney P (1979) Worsening of diabetes in men with impaired glucose tolerance. Diabetologia 16:25-30

4. World Health Organization Study Group (1999) Report of a WHO consultation Part 1: Definition, Diagnosis and Classification of Diabetes Mellitus and its Complications. World Health Organization, Geneva, p 59

5. Expert Committee on the Diagnosis and Classification of Diabetes Mellitus (2004) Summary of revisions for the 2004 clinical practice recommendations. Diabetes Care 27 [Suppl 1]:S5-S14

6. Balkau B, Shipley M, Jarrett RJ et al (1998) High blood glucose concentration is a risk factor for mortality in middle-aged nondiabetic men. 20-year follow-up in the Whitehall Study, the Paris Prospective Study, and the Helsinki Policemen Study. Diabetes Care 21:360-367

7. Haffner SM (1998) The importance of hyperglycemia in the nonfasting state to the development of cardiovascular disease. Endocr Rev 19:583-592

8. Bonora E, Kiechl S, Willeit J et al (2004) Population-based incidence rates and risk factors for type 2 diabetes in white individuals. The Bruneck Study. Diabetes 53:1782-1789

9. Rodriguez BL, Lau N, Burchfiel CM et al (1999) Glucose intolerance and 23-years risk of coronary heart disease and total mortality. The Honolulu Heart Program. Diabetes Care 22:920 924
10. Fuller JH, Shipley MJ, Rose G, Jarrett RJ, Keen H (1980) Coronary-heart-disease risk and impaired glucose tolerance. The Whitehall Study. Lancet 1:1373-1376

11. Coutinho M, Gerstein HC, Wang Y, Yusuf S (1999) The relationship between glucose and incident cardiovascular events: a metaregression analysis of published data from 20 studies of 95,783 individuals followed for 12.4 years. Diabetes Care 22: 233-240

12. Pratley RE, Weyer C (2001) The role of impaired early insulin secretion in the pathogenesis of type II diabetes mellitus. Diabetologia 44:929-945

13. Resnick HE, Harris MI, Dwight BB, Harris TB (2000) American Diabetes Association diabetes diagnosis criteria, advancing age, and cardiovascular disease risk profiles. Diabetes Care 23:176-180

14. Krauss RM, Winston M, Fletcher RN, Grundy SM (1998) Obesity: impact of cardiovascular disease. Circulation 98:14721476

15. Expert Committee on the Diagnosis and Classification of Diabetes Mellitus (1997) Report of the Expert Committee on the Diagnosis and Classification of Diabetes Mellitus. Diabetes Care 20:1183-1197

16. Ceriello A (2003) The possible role of postprandial hyperglycaemia in the pathogenesis of diabetic complications. Diabetologia 46 [Suppl 1]:M9-M16

17. DECODE Study Group on behalf of the European Diabetes Epidemiology Study Group (2003) Is the current definition for diabetes relevant to mortality risk from all causes and cardiovascular and noncardiovascular diseases? Diabetes Care 26:688696

18. Hanefeld M, Koehler C, Henkel E, Fuecker K, Schaper F, Temelkova-Kurktschiev T (2000) Post-challenge hyperglycaemia relates more strongly than fasting hyperglycaemia with carotid intima-media thickness: the RIAD Study. Risk Factors in Impaired Glucose Tolerance for Atherosclerosis and Diabetes. Diabet Med 17:835-840

19. Bouchard C (1996) Genetics, epidemiology, association, and sib-pair linkage: results from the Québec Family Study. In: Bray GA, Ryan DH (eds) Molecular and genetic aspects of obesity. Louisiana State University Press, Baton Rouge, pp 470-481

20. Meneely GR, Kaltreider NL (1949) Volume of the lung determined by helium dilution. J Clin Invest 28:129-139

21. Siri WE (1956) The gross composition of the body. Adv Biol Med Phys 4:239-280

22. The Airlie (VA) Consensus Conference (1988) In: Lohman T, Roche A, Martorel R (eds) Standardization of anthropometric measurements. Human Kinetics Publishers, Champaign, pp 39 80

23. Sjöström L, Kvist H, Cederblad A, Tylen U (1986) Determination of total adipose tissue and body fat in women by computed tomography, 40K and tritium. Am J Physiol 250:E736-E745

24. Ferland M, Després JP, Tremblay A et al (1989) Assessment of adipose tissue distribution by computed axial tomography in obese women: association with body density and anthropometric measurements. Br J Nutr 61:139-148

25. Richterich R, Dauwalder H (1971) Determination of plasma glucose by hexokinase-glucose-6-phosphate dehydrogenase method [in German]. Schweiz Med Wochenschr 101:615-618

26. Desbuquois B, Aurbach GD (1971) Use polyethylene glycol to separate free and antibody-bound peptide hormones in radioimmunoassays. J Clin Endocrinol Metab 37:732-738

27. Heding LG (1975) Immunological determination of human C-peptide in serum. Diabetologia 11:541-548

28. Pascot A, Després JP, Lemieux I et al (2000) Contribution of visceral obesity to the deterioration of the metabolic risk profile in men with impaired glucose tolerance. Diabetologia 43:11261135

29. Matthews DR, Hosker JP, Rudenski AS, Naylor BA, Treacher DF, Turner RC (1985) Homeostasis model assessment: insulin resistance and beta-cell function from fasting plasma glucose and insulin concentrations in man. Diabetologia 28:412-419 
30. Stumvoll M, Mitrakou A, Pimenta W et al (2000) Use of the oral glucose tolerance test to assess insulin release and insulin sensitivity. Diabetes Care 23:295-301

31. Seltzer HS, Allen W, Herron AL, Brennan MT (1967) Insulin secretion in response to glycemic stimulus: relation of delayed initial release to carbohydrate intolerance in mild diabetes mellitus. J Clin Invest 46:323-334

32. Hanson RL, Pratley RE, Bogardus C et al (2000) Evaluation of simple indices of insulin sensitivity and insulin secretion for use in epidemiologic studies. Am J Epidemiol 151:190-198

33. Bergstrom RW, Wahl PW, Leonetti DL, Fujimoto WY (1990) Association of fasting glucose levels with a delayed secretion of insulin after oral glucose in subjects with glucose intolerance. J Clin Endocrinol Metab 71:1447-1453

34. Cederholm J, Wibell L (1990) Insulin release and peripheral sensitivity at the oral glucose tolerance test. Diabetes Res Clin Pract 10:167-175

35. Matsuda M, DeFronzo RA (1999) Insulin sensitivity indices obtained from oral glucose tolerance testing: comparison with euglycemic insulin clamp. Diabetes Care 22:1462-1470

36. Couillard C, Després JP, Lamarche B et al (2001) Effects of endurance exercise training on plasma HDL cholesterol levels depend on levels of triglycerides: evidence from men of the Health, Risk Factors, Exercise Training and Genetics (HERITAGE) Family Study. Arterioscler Thromb Vasc Biol 21:1226-1232
37. Laurell CB (1966) Quantitative estimation of proteins by electrophoresis in agarose gel containing antibodies. Anal Biochem $15: 45-52$

38. Bosello O, Zamboni M (2000) Visceral obesity and metabolic syndrome. Obes Rev 1:47-56

39. Weyer C, Bogardus C, Mott DM, Pratley RE (1999) The natural history of insulin secretory dysfunction and insulin resistance in the pathogenesis of type 2 diabetes mellitus. J Clin Invest 104:787-794

40. Kahn SE, Prigeon RL, McCulloch DK et al (1993) Quantification of the relationship between insulin sensitivity and beta cell function in human subjects: evidence for a hyperbolic function. Diabetes 42:1663-1672

41. Bergman RN, Phillips LS, Cobelli C (1981) Physiologic evaluation of factors controlling glucose tolerance in man: measurement of insulin sensitivity and beta-cell glucose sensitivity from the response to intravenous glucose. J Clin Invest 68:14561467

42. Weyer C, Bogardus C, Pratley RE (1999) Metabolic characteristics of individuals with impaired fasting glucose and/or impaired glucose tolerance. Diabetes 48:2197-2203

43. Festa A, D'Agostino R, Hanley A, Karter AJ, Saad MF, Haffner SM (2004) Differences in insulin resistance in nondiabetic subjects with isolated impaired glucose tolerance or isolated impaired fasting glucose. Diabetes 53:1549-1555 